\title{
The Effects of Iron Filling On Some Mechanical and Physical Properties of a Sawdust Particleboard
}

\author{
*P. A. P. Mamza' ${ }^{1}$ A. Aliu ${ }^{2}$ and R. A. Muhammad ${ }^{2}$ \\ ${ }^{1}$ Department of Chemistry, ${ }^{2}$ Department of Metallurgical Engineering, Ahmadu Bello \\ University, Zaria, Nigeria. \\ ["mamzapaul@yahoo.com, fax number-+2348053430363]
}

\begin{abstract}
This research work was aimed at producing particleboard from sawdust (matrix) and iron filling (particulate) under the same conditions as ordinary particleboard produced from sawdust alone and their properties compared. Sawdust -iron fillings particleboards were produced using a sawdust of particle size $1.18 \mathrm{~mm}$ and iron fillings of size $300 \mu \mathrm{m}, 20 \mathrm{~g}$ binder (urea formaldehyde) concentration, hot pressing temperature of $160^{\circ} \mathrm{C}$, applied pressure of 10 tons equivalent to $12.5 \mathrm{Mpa}$, hot pressing time of 12 minutes throughout the production of the particleboards. The weight of sawdust was kept constant $(50 \mathrm{~g})$ while the weight of iron filling was varied (i.e from 10, 20, 30, 40 and 50g). A controlled sample of only sawdust particleboard was produced and tested under the same condition as those of the sawdust- iron filling particleboard. The mechanical properties tested showed that the particleboard from 40g iron filling has the highest mechanical properties (MOR, MOE and UTS of $255.20 \mathrm{Mpa}, 432.43 \mathrm{Mpa}$ and 22Mpa). Particleboard produced from only sawdust alone was found to have the least mechanical properties that is MOR, MOE and UTS of $140.63 \mathrm{Mpa}, 46.19 \mathrm{Mpa}$ and $7 \mathrm{Mpa}$ respectively. The water absorption and thickness swell test results showed that the particleboard of $40 \mathrm{~g}$ iron fillings has the highest water resistance capacity and least thickness swell of $33.69 \%$ and $5.87 \%$ respectively.
\end{abstract}

\section{INTRODUCTION}

Particleboard: A generic term for a panel manufactured from lignocelluloses materials (usually wood) primarily in the form of discrete pieces or particles, as distinguished from fibers, combined with a synthetic resin or other suitable binder and bonded together under heat pressure in a hot press by a process in which the entire interparticle bond is created by the added binder, and to which other materials may have been added during manufacture to improve certain properties. Particleboards are further defined by the method of pressing. When the pressure is applied in the direction perpendicular to the faces as in a conventional multiplaten hot press, they are defined as flatplaten presses and when the applied pressure is parallel to the faces, they are defined as extrude(Mamza et al.; 2008).

These newer materials are similar to paper in principle, however, chemistry is not the dominant discipline, and the basic wood element is much larger. The properties are controlled not only by the composition and structure achieved by means of these elements, but also by the quality of binding achieved between elements during processing. It is of interest that a simple application of just this one principle of materials science, i.e., control of properties through composition and structure, launched an industry that grew rapidly with very little input of wood sciences or any other science. In recent years, many different sciences have been brought to bear and are beginning to foster a more rapid adoption of a materials science approach (www.niir.org/books; 2005). Perhaps the most important concept involved in these materials is that the basic wood elements possess distinctive qualities of their own, analogous to chemical elements. These qualities emanate primarily from their geometry and their size. Composition is expressed by the particular elements chosen for the material and the relative amounts of each, together with other additives, such as adhesives, waxes, and fire retardants. Structure is expressed by the location of the 
various elements through the thickness of the material, by the degree of compaction, and by the density profile. Another important factor in structure is the degree of alignment of the elements prescribed in various layers of the materials during manufacture. For example, flakes confer high values of modulus of rupture (MOR) and modulus of elasticity (MOE), but low values of tension perpendicular to the board surface (internal bond, IB). On the other hand, particles confer low MOR and MOE, but high IB (www.niir.org/books; 2005).

Knowledge of such basic characteristics of wood elements can lead to many innovative combinations, some what analogous to alloys in metallurgy. In addition, any elongated element can be oriented, and such orientation can be confined to certain layers of the board for maximum effect. This action significantly increases the MOR and MOE in the direction of orientation while lowering the properties in the perpendicular direction, with ratio as high as 9:1. The IB, however, is unchanged. With further development, some of these oriented materials may well exceed nature's best effort. This is why we are investigating the effect of iron filling ( the dispersed phase) as filler in the matrix of sawdust particle with ureaformaldehyde (binder) to produce a particleboard which we expect to have a higher mechanical property that will be better than ordinary particleboard made by the same process without the iron filling (www.niir.org/books; 2005). Normally, the manufacturing process for these materials requires a step in which both heat and pressure are applied to consolidate the material and cure the adhesive. This action results in an increase in density above the density of the starting raw material. Control of processing variables is very critical in the manufacture of these materials, and production plants have become quite sophisticated. Electronic instrumentation and computers are common in most new installations. Composition and structure 1 are both controlled to produce desired properties. Fracture mechanics, another important area in materials science, but practically untouched in wood science, will be needed in the generation of the wood elements from larger pieces, and in fracture occurring as consequence of overload stresses (www.niir.org/books; 2005).

Particleboard Production from Different Materials: Agricultural residues are renewable resources that can be utilized as raw materials for particleboard manufacturing (Wang and Sun.; 2002). Research has been carried out on wide varieties of agricultural residues from many different regions of the world; wheatcereals shrubs (Mosesson; 2008).

There was a report that increasing the shelling ratio improves the physical and mechanical properties of particleboards. When acidcatalyzed resin was cross linked a proportional loss in mechanical strength was observed, but the alkaline cured polymer is more effective in this (Adajineh; 2008).

A report shows that the treatment of wood (sawdust) and other particles with a thermosetting resin increase the mechanical properties of particleboards (Deka and Saikia; 2000).

Investigation carried out on the variation in mechanical properties of a particleboard made from sawdust due to the variation of percentage composition of urea formaldehyde revealed that at $30 \%$ to $32 \%$ resins concentration, the best mechanical properties were achieved(Mamza and Shadrach; 2008 ).

A study carried out shows that a particleboard made from sugarcane, bagasse was depicted in a special machine in two stages, dried, mixed with a binder and hot pressed in the same condition as boards made from wood particles. The boards produced have mechanical properties that are comparable to those of similar boards made of jute, sticks, hemp shives and various wood species (Adajineh; 2008)

The suitability of bagasse and other lignocellulosic residues, such as flax shives, rape straw, reed, sunflower, seek husks, and groundnut shells, such as raw material for particleboards was studied. The physical properties of boards prepared from various residues on a laboratory scale were tabulated. Single layer as well as three layer boards of different material was prepared using 5-12\% urea formaldehyde resin as a binder. Satisfactory products were obtained by pressing 
the material at $160^{\circ} \mathrm{C}$ and $1.5 \mathrm{Mpa}$ for 6 to 10min (Abdul; 1998).

In this investigation, thermosetting resins was produced from condensation of urea and formaldehyde in an alkaline condition and filled with sawdust and varying percentage composition of iron fillings.

Properties of a particleboard: Properties of the particleboard that are of relevance to the standard or applicability of the board include the following:

Iron Fillings: "Iron filings" means small particles of metal produced by the filing or grinding of ferrous metal. Fillings in the limited sense of the word are used in the interests of economy, part of the expensive plastic being replaced by a cheaper material. They are finely powdered, naturally occurring non-polymeric materials. They are intimately mixed with the sawdust which builds them in a uniform mass. The amount of filler used is determined by its effect on the properties and the extent to which this can be tolerated. Powdered metals are obviously not cost-reducing fillers, and are used in the production of materials with special and desirable properties.

The plastics used are almost entirely thermosetting, but in this case, they are usually of the hot-curing type. In most cases the metal is used to modify some of the properties of the particleboard, usually thermal, and mechanical properties

Iron and steel powder are widely used in the manufacture of epoxy resin tools, which could otherwise overheat. Iron and steel filled plastics have many electrical uses, most of which make use of the magnetic properties. The advantage of this type of magnetic material include: easier fabrication into complex shapes, reduction and better control of eddy currents and an increase in resistance to corrosion Nodular cast iron has a Modulus of Elasticity of 159-172 Gpa (Callister; 2000).

\section{MATERIAL AND METHODS}

List of Materials: The Materials used are as follows

i. Sawdust (1.18mm dia)

ii. Urea formaldehyde resin iii. Iron fillings $(300 \mu \mathrm{m})$

iv. Water used for testing water absorption and thickness swelling

Equipment used in testing the mechanical strength of the particleboard produced is as follows:

i. Artist saw, used for cutting of the particleboards into rectangular shape.

ii. Universal Testing Machine (500 tons capacity) for testing the breaking load $(\mathrm{KN})$, Elongation (mm), Tensile strength (Mpa) and \% elongation of the specimens.

Experimental Methods: The laboratory work was carried out by the following steps:

i. Collection of the raw materials

ii. Removal of dirt and unwanted materials (beneficiation)

iii. Drying of the sawdust

iv. Grinding of the sawdust to the desirable size

v. Sieving of the ground sawdust to obtain

$1.18 \mathrm{~mm}$ passing particle size

vi. Sieving of iron fillings to obtain $300 \mu \mathrm{m}$ passing particle size

vii. Production of the particleboard

viii. Testing of the particleboard produced for absorption, thickness swell and mechanical properties.

The steps listed above shall be discussed in detail below:

Collection of The Raw Materials: The raw materials used in this investigation are sawdust, iron fillings and urea formaldehyde.

Iron fillings: The iron fillings used in this investigation was obtained from Mechanical Engineering (A B U, Zaria) workshop immediately after some machine components were grinded. This was done to avoid the use of rusted iron fillings which could affect the results of the investigation.

The iron fillings were sieved to a particle size of $300 \mu \mathrm{m}$ passing, retained at $150 \mu \mathrm{m}$ mesh size by using a sieve of $300 \mu \mathrm{m}$ and $150 \mu \mathrm{m}$ which were $75 \mathrm{~cm}$ in diameter. The sieving was carried out in Building Department (A B U, Zaria).

The chemical composition of the machined nodular cast iron from which the iron fillings was obtained is shown in the table below: These suggest that the iron filling has the same chemical composition as its parent nodular cast iron. 
Table 3.3: Chemical composition the iron fillings

\begin{tabular}{ll}
\hline Elements & Composition (\%) \\
\hline Carbon & 3.53 \\
Silicon & 2.67 \\
Magnesium & 0.05 \\
Sulfur & 0.01 \\
Phosphorus & 0.03 \\
Manganese & 0.31 \\
Iron & 93.40 \\
\hline
\end{tabular}

The sieved iron filling was measured in a weighing balance and it weighed $465 \mathrm{~g}$. It was safely kept for further procedures.

Sawdust: The sawdust used in this investigation was obtained from a matured hard wood Doka (local name) grown in the rain forest zone of West Africa, Southern part of Nigeria (Ibadan, Oyo State). The sawdust was obtained directly from a sawmill factory, dried under the sun in an open air to a moisture content of $6 \%$. A communition process was carried out to reduce the sawdust to a smaller particle size in other to have effective beneficiation. The sawdust was then sieved to a particle size of $1.18 \mathrm{~mm}$ passing, retained at $900 \mu \mathrm{m}$ by using a sieve of $1.18 \mathrm{~mm}$ and $900 \mu \mathrm{m}$ mesh sizes. The sieves were obtained from Building department (A B U, Zaria) and the sieving was equally conducted in the same department. The under sized and over sized particles were discarded. The prepared particles were weighed in the weighing balance and it weighed $1 \mathrm{~kg}$. It was kept for further procedure (i.e blending).

Urea formaldehyde: The urea formaldehyde used in this investigation was prepared at National Research Institute for Chemical Technology (NARICT), Zaria.

Urea formaldehyde was prepared by adjusting the $\mathrm{P}^{\mathrm{H}}$ of $130 \mathrm{~g}$ formaldehyde $(38 \%)$ to 7.5 with an aqueous solution of $\mathrm{NaOH}(10 \%)$ and $60 \mathrm{~g}$ urea was added. The mixture was stirred and heated under flux for 2hours. Then about $40 \mathrm{ml}$ $\mathrm{H}_{2} \mathrm{O}$ was diluted off to obtain a resin of $70 \%$ solids, $2.7 \%$ free formaldehyde, and $9.4 \% \mathrm{~N}$ - methylol formaldehyde. Thus obtained liquid resin was treated with $0.3 \mathrm{~N}$ acetic acid to a $\mathrm{P}^{\mathrm{H}}$ of 4.0 and cured under reflux for additional 3hours. The moisture content of gelled product was found by drying it at $45-50^{\circ} \mathrm{C}$ and 0.1 $0.2 \mathrm{kpa}$ for 2-3hours.

\section{The Production of the Particleboard}

The particleboards were produced by the following procedure:

i. 50g of the prepared sawdust above were carefully measured into six containers ready for blending process

ii. $15 \mathrm{~g}(30 \%)$ of urea formaldehyde were measured into six different plastic containers

iii. $10 \mathrm{~g}, 20 \mathrm{~g}, 30 \mathrm{~g}, 40 \mathrm{~g}$, and $50 \mathrm{~g}$ of the prepared iron filling produced above wer measured and kept ready for blending.

iv. One of the $50 \mathrm{~g}$ sawdust was mixed with $20 \mathrm{~g}$ of urea formaldehyde and blended thoroughly to enhance homogeneity before pressing operation. It was then spread on a metal plate (the mold) which was covered with an aluminum foil. The aluminum foil was folded to enclose the sawdust between the two metal plates. The metal plates with its content were placed on the hydraulic hot press machine which has been heated to a temperature of $160^{\circ} \mathrm{C}$. A pressure load of 10tons was applied for 12 mins to allow the resins to fully cure (Deppe and Ernest; 1986). A particleboard finally produced was kept for testing operation. This serves as a controlled sample.

v. Each of the measured iron filling in (iii) above were mixed thoroughly with $50 \mathrm{~g}$ of the prepared sawdust and $20 \mathrm{~g}$ of urea formaldehyde. The process in (iv) above was repeated for each samples. Each samples produced was kept for testing procedure.

The Testing Methods Adopted on the Particleboard Produced

1. Testing for tensile strength: The tensile strength of the particleboards produced above was determined through the following procedure:

i. Each of the produced boards above was cut into a rectangular shape of dimensions $20 \mathrm{~mm} x$ $50 \mathrm{~mm}$. Two samples were cut for testing from each particleboard produced in other to enhance accuracy in measurement. The thickness of each 
samples were measured and recorded as shown in the tables in chapter four below.

ii. Each prepared samples in (i) were fixed in a grip of a universal testing machine (500tons capacity) and then loaded automatically from the computer. The graph of load/ extension was plotted on the computer screen. Two samples from each of the particleboard produced were tested by the same process and the average results were taking to maximize accuracy. The results were printed out and tabulated as shown in the tables in chapter four below.

2. Testing water absorption: A sample from each of the particleboard produced was taking and weighed in a top loading digital weighing balance (in Chemistry Department). They were

\section{RESULTS}
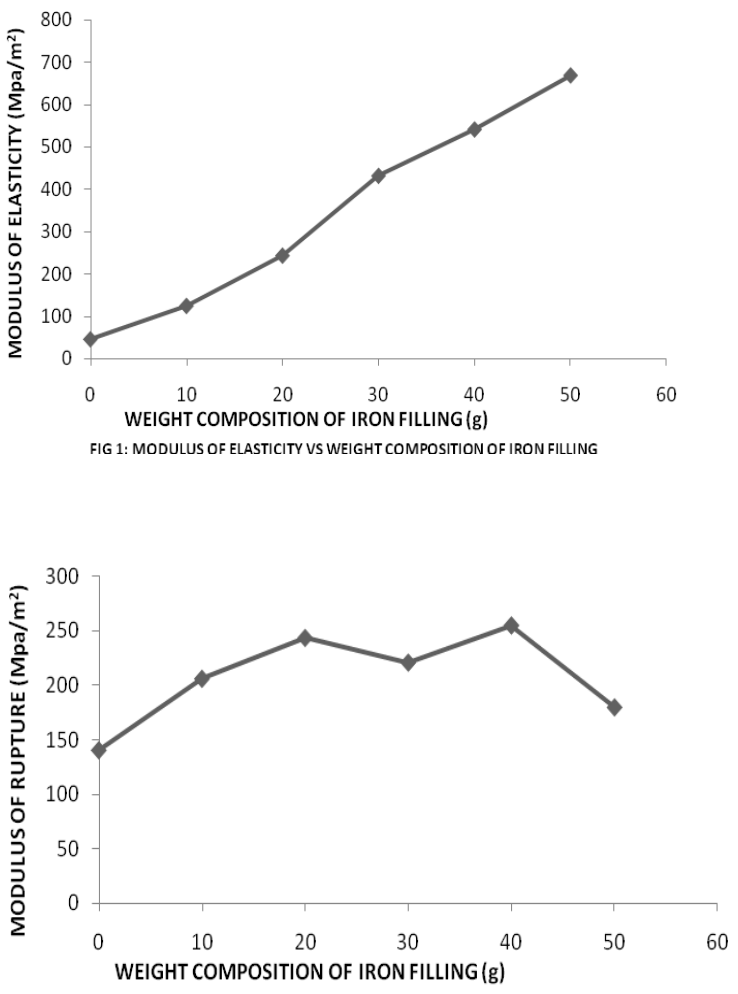

FIG 2: MODULUS OF RUPTURE VS WEIGHT COMPOSITION OF IRON FILLING then soaked in water for 24hours. Each of them was weighed again in the same apparatus. The ratio of the difference in weight to the original weight of the sample expressed as a percentage is the water absorption and was calculated each of the board formed above.

3. Testing for thickness swelling: The thickness of each of the samples in (2) above was measured before soaked in water for 24hours and the thickness after soaked for 24hours. The ratio of the differences in thickness to the original thickness of the sample expressed as a percentage is the thickness swell which was determined for each of the boards formed above

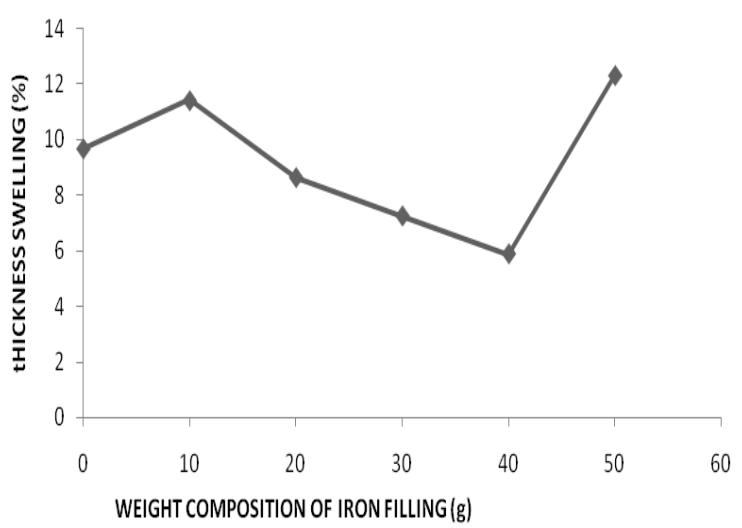

FiG4 THICKNESS SWELLING VS WEIGHT COMPOSITION OF IRON FILLING

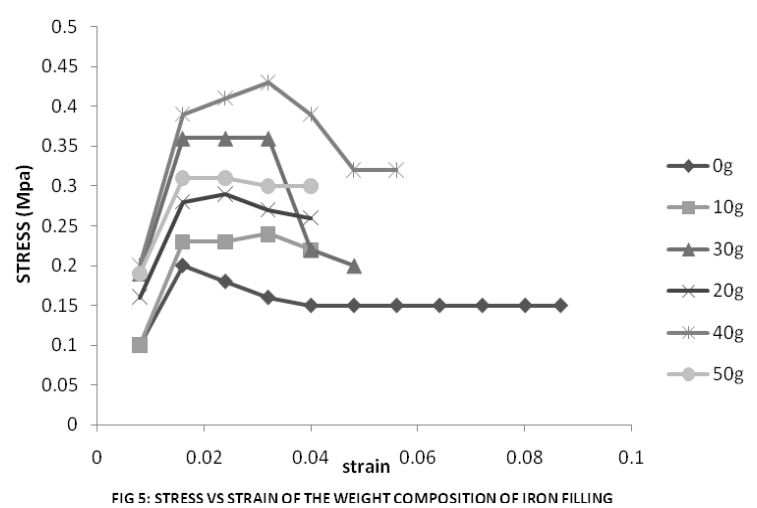




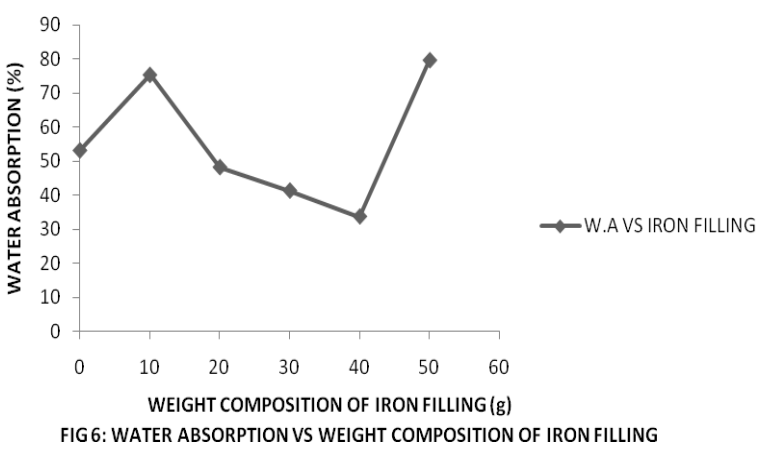

\section{DISCUSSION}

It can be observed that the thickness of the samples started to increase from $2 \mathrm{~mm}$ in control sample, $10 \mathrm{~g}$ and $20 \mathrm{~g}$ weight composition of iron filling to 2.1,2.3 and 2.5 in 30,40 and $50 \mathrm{~g}$ weight composition of iron filling respectively. There was no increase in Table 1: The dimensions of the Tested samples.

\begin{tabular}{llllll}
\hline S/ No & $\begin{array}{l}\text { Weight of } \\
\text { iron } \\
\text { filling(g) }\end{array}$ & $\begin{array}{l}\text { Length of the } \\
\text { sample }(\mathrm{m})\end{array}$ & $\begin{array}{l}\text { Width of the } \\
\text { sample }(\mathrm{m})\end{array}$ & $\begin{array}{l}\text { Thickness } \\
\text { of } \\
\text { sample }(\mathrm{m})\end{array}$ & $\begin{array}{l}\text { Cross sectional } \\
\text { Area }\left(\mathrm{m}^{2}\right)\end{array}$ \\
\hline 1 & Control & 0.05 & 0.02 & 0.002 & $4.0 \times 10^{-5}$ \\
2 & 10 & 0.05 & 0.02 & 0.002 & $4.0 \times 10^{-5}$ \\
3 & 20 & 0.05 & 0.02 & 0.002 & $4.2 \times 10^{-5}$ \\
4 & 30 & 0.05 & 0.02 & 0.0021 & $4.6 \times 10^{-5}$ \\
5 & 40 & 0.05 & 0.02 & 0.0023 & $5.0 \times 10^{-5}$ \\
6 & 50 & 0.05 & 0.02 & 0.0025 & $4.0 \times 10^{-5}$ \\
\hline
\end{tabular}

Table 2: Tensile strength of the tested samples.

\begin{tabular}{lllllll}
\hline S/No & $\begin{array}{l}\text { Weight } \\
\text { composition of } \\
\text { iron filling }(\mathrm{g})\end{array}$ & $\begin{array}{l}\text { modulus of } \\
\text { elasticity } \\
\left(\mathrm{Mpa} / \mathrm{m}^{2}\right)\end{array}$ & $\begin{array}{l}\text { tensile } \\
\text { strength } \\
(\mathrm{Mpa})\end{array}$ & $\begin{array}{l}\% \\
\text { Elong }\end{array}$ & $\begin{array}{l}\text { Elon\% } \\
\text { \%Elong }\end{array}$ & $\begin{array}{l}\text { Ultimat } \\
\text { e strain }\end{array}$ \\
\hline 1 & control & 46.19 & 4 & 8.66 & 4.33 & 0.0866 \\
2 & 10 & 125.00 & 7 & 2.7 & 1.35 & 0.0560 \\
3 & 20 & 243.90 & 10 & 4.68 & 2.34 & 0.0410 \\
4 & 30 & 432.43 & 16 & 3.7 & 1.85 & 0.0370 \\
5 & 40 & 541.87 & 22 & 4.06 & 2.03 & 0.0406 \\
6 & 50 & 669.64 & 15 & 2.24 & 1.12 & 0.0224 \\
\hline
\end{tabular}

Table 3: The modulus of Rupture (MR) result for the tested samples

\begin{tabular}{llllllll}
\hline S/No & $\begin{array}{l}\text { Weight composition } \\
\text { of iron filling }(\mathrm{g})\end{array}$ & $\begin{array}{l}\text { length of the } \\
\text { sample } \mathrm{L}(\mathrm{m})\end{array}$ & $\begin{array}{l}\text { width } \\
(\mathrm{m})\end{array}$ & $\begin{array}{l}\text { Depth } \\
(\mathrm{m})\end{array}$ & $\begin{array}{l}\mathrm{d}) \\
\text { control }\end{array}$ & $\begin{array}{l}\text { breaking } \\
\text { load }(\mathrm{KN})\end{array}$ & $\begin{array}{l}\text { Modulus } \\
\text { rupture }\left(\mathrm{Mpa} / \mathrm{m}^{2}\right)\end{array}$ \\
10 & 0.05 & 0.02 & 0.002 & 0.15 & 140.63 \\
20 & 0.05 & 0.02 & 0.002 & 0.22 & 206.25 \\
30 & 0.05 & 0.02 & 0.002 & 0.26 & 243.75 \\
40 & 0.05 & 0.02 & 0.0021 & 0.26 & 221.09 \\
50 & 0.05 & 0.02 & 0.0023 & 0.36 & 255.20 \\
& & 0.02 & 0.0025 & 0.30 & 180.00 \\
\hline
\end{tabular}

volume of samples 2 and 3 because the iron filling in those samples and hence could not cause any significant increase in volume as a result of high compressive load of the pressing machine which subject the iron filling to occupy some intersticial spaces between the sawdust particles. Therefore the volume remain the same but it causes a significant increase in the mechanical properties of the samples (i.e Modulus of Elasticity (M O E), Tensile Strenght and Modulus of Rupture (M O R) of the samples) as shown in Fig.1,2and 3 respectively. The mechanical properties increases because the iron fillings in the interstitial spaces disallow the slipping of sawdust Particles over each other when it undergoes tensile loading. 
Table 4: Water absorption of the iron filling particleboard produced

\begin{tabular}{lllll}
\hline S/No & $\begin{array}{l}\text { Weight composition } \\
\text { of iron filling }(\mathrm{g})\end{array}$ & $\begin{array}{l}\text { Weight before } \\
\text { soaking in water }(\mathrm{g})\end{array}$ & $\begin{array}{l}\text { Weight after soaking in } \\
\text { water }(\mathrm{g})\end{array}$ & $\begin{array}{l}\text { Water } \\
(\%)\end{array}$ \\
\hline 1 & control & 0.94 & 1.44 & 53.19 \\
2 & 10 & 1.96 & 2.90 & 75.49 \\
3 & 20 & 2.28 & 3.38 & 48.25 \\
4 & 30 & 2.66 & 3.76 & 41.35 \\
5 & 40 & 3.74 & 5.00 & 33.69 \\
6 & 50 & 2.38 & 4.28 & 79.83 \\
\hline
\end{tabular}

Table 5: Thickness Swell of the Particleboard Produced

\begin{tabular}{llllll}
\hline S/No & $\begin{array}{l}\text { Weight composition } \\
\text { of iron filling }(\mathrm{g})\end{array}$ & $\begin{array}{l}\text { Thickness } \\
(\mathrm{mm})\end{array}$ & before & Thickness after & $\begin{array}{l}\text { Thickness } \\
\text { swell }(\%)\end{array}$ \\
\hline 1 & control & 2 & 2.44 & 9.67 \\
2 & 10 & 2 & 2.50 & 11.41 \\
3 & 20 & 2 & 3.00 & 8.63 \\
4 & 30 & 2.1 & 3.35 & 7.24 \\
5 & 40 & 2.3 & 3.10 & 5.87 \\
6 & 50 & 2.5 & 3.19 & 12.32 \\
\hline
\end{tabular}

It can be observed that there was a significant increase in the thickness of the samples 3,4 and 5 (i.e $30 \mathrm{~g}, 40 \mathrm{~g}$ and $50 \mathrm{~g}$ weight composition of iron fillings, this could be attributed to the available interstitial spaces between the sawdust particles which were filled with iron fillings thereby causing an increase in the volume of the particleboard produced. This had resulted into a higher impedement of the movement of dislocation. This was clearly shown in Fig. 1 whereby the Modulus of Elasticity (Stiffness) of the samples continued to increase with increase in weight composition of iron fillings. Also in Fig 2, the Modulus of Rupture of the samples increases with increase in weight composition of iron filling and the highest was obtained at $40 \mathrm{~g}$ iron filling, but a change was noticed at 50g iron filling where the Modulus of Rupture was found to decrease implying somewhat that a critical composition of iron filling had been exceeded. This is in line with what was observed in Fig.5 where the sample 50g had a lower breaking stress than that of sample 40 and $30 \mathrm{~g}$.

It can also be observed that sample $50 \mathrm{~g}$ had the highest percentage water absorption (79.83\%). This could be due to the weak iron to iron bonding force in the sample as a result of high volume of iron filling in the sample. Sample $40 \mathrm{~g}$ has the lowest percentage of water absorption $(33.69 \%)$, possibly because of its maximum binding force between the iron filling and sawdust particle and nearly complete filling of the pores by the iron fillings which could limit the water absorption by capillary action.

From Table 5, it could be seen that sample $50 \mathrm{~g}$ had the highest thickness swelling which could be due to its high percentage water absorption as can equally be seen in Fig 4 above. Sample 40g had the lowest percentage thickness swelling which could be as a result of the strong binding force between the iron filling and the sawdust particles. The sample $30 \mathrm{~g}$ was next least in percentage thickness swelling followed by $20 \mathrm{~g}$ for the same 
possible reasons. The binder used in the production of this particleboard is itself nonwater resisting (Deppe,1986) which could be attributed to the high percentage water absorption and thickness swelling of the produced particleboard.

Conclusions: The following conclusions were drawn based on the results obtained from the work: The mechanical properties of the samples produced shows that sample 4 (40g iron filling ) exhibit the best mechanical properties followed by sample 3 (30g iron filling). The result actually shows that particleboard produced from sawdust mixed with iron filling has a better mechanical properties than those produced from sawdust alone under the same condition.

The particleboard produced (ranging from samples 10,20,30 and 40g iron filling ) meet the international standard for Hardboard products in terms of mechanical properties since the class 1 hardboard has a maximum M O R of $48.3 \mathrm{Mpa}$, tensile strength of 18 Mpa. Therefore the boards are suitable for siding, trimming, roofing tiles, door panel and partitioning of buildings and offices.

The particleboard produced with $40 \mathrm{~g}$ iron filling in 50g sawdust matrix was observed to have the highest water resisting ability and dimensional stability compared to others. Hence for application requiring board usage in humid areas, this particleboard is best adaptive.

The sample 5 (50g iron filling) is only highest in modulus of elasticity (stiffness) but weak in strength and M O R (toughness). Therefore it has a poor mechanical properties and low application. It also has the lowest water resisting ability and dimensional stability.

\section{ACKNOWLEDGEMENT}

One of the authors, Paul A. P. Mamza is indebted to Ahmadu Bello University, Zaria for financial assistance.

\section{REFERENCES}

Adajineh,F., 2008, "Production of particleboard composite from sugarcane bark and Baggasse", Unpublished Research project, Chemical Engineering Department, A. B. U, Zaria. Nigeria.

Abdul,N, 1998, "Particleboard formation under higher temperature and pressure", Unpublished Research project, Chemical Engineering Department, A. B. U. Zaria. Nigeria.

Callister, D. W, 2000, Materials Science and Engineering, An Introduction, John Wiley and Sons Inc, New York. 511-514, 776-777.

Daniel M.I. and Ishai. O, 1994, Engineering of Composite Materials, Published in Oxford University.

Deppe, H.J, and Ernst, K, 1986, "Reducing Particleboard Pressing Time", An Exploratory study, U.S Dept. of Agriculture Forest Service, Madison, 3-14 USA.

Deka, M.and Saikia, C. N, 2000, "Effects of Amino Resin Treatment on Dimensional Stability, Bio Researches Technology 73, 179-181.

Mark H. F, Bikales M. N, Overberger C. G and Menges G., 1990, Encyclopedia of Applied Polymer Science and Engineering, $2^{\text {nd }}$ ed., John Wiley, New York, 4, 47-64.

Mamza, P, A. P, Peters, O.A and Amupitan, J.O. 1995, "Effects of catalyst on some mechanical and

physicochemical properties of filled Urea Formaldehyde". Proceedings of the Science Association of Nigeria. 19, 244-247.

Mamza, P. A. P and Shadrach, K..2008, "The Mechanical Properties of Urea Formaldehyde Particleboards", International Journal of Pure and Applied Sciences, 2, 16-27.

Mosesson, J. G,1980, "The processing and use of straw as constructional Material". Conservation and reserving 3: 369-412.

Wang, D. and Sun, X. N.2002, "Low density particleboard from wheat Straw and corn pith" Industrial crops and products.15, 47-50.

www.niir.org/books/book/zb,2005, "The Complete Technology Book on Wood and Its Derivative". National Institute of Industrial Research. 